\title{
Psychoimmunology before its time
}

\section{That there is probably a link between the central nervous system and the immune system is easily accepted. The doubt is whether enough is yet known to sustain people's hopes of explanation.}

THE notion that emotional disturbance may trigger off physical illness is in no sense new. That people may be driven by adversity into decline is a familiar theme in literature. Strictly speaking, the phenomenon is distinct from that of psychosomatic illness such as Freud's well-documented cases of hysterical paralysis in which, in Freudian terms, the illness is a kind of talisman for the emotional disturbance. Instead, the physical consequences of emotional shock may become manifest in normal people even if they are more spectacular among those with an underlying emotional disturbance.

Over two decades, Professor G.W. Brown of Bedford College, University of London, has been collecting evidence that what he calls life-events (imprisonment, relocation or personal bankruptcy, for example) may provoke illness in outwardly normal people. The speed with which a person's death will follow that of his or her spouse is the most familiar occurrence of this kind. The pattern is familiar, but the mechanism is unknown.

That, at least, has been the state of affairs until quite recently. Now, as some of the new generation of medical students know perhaps too well, there is emerging a speciality called psychoimmunology - a means of explaining such phenomena as the increased risk of death on bereavement in terms of the disturbance caused to the immune system in the wake of emotional shock or deprivation. The difficulty, for the rest of us, is that of knowing just what weight to give to these accounts.

That there should be a functional connection between the central nervous system and the immune system is not in itself surprising. In animals, neurophysiologists now have a lot to say about the way in which the brain controls the system of locomotion, while the regulation of the reproductive system in mammals by means of the peptide hormones involved in the regulation of the pituitary gland by the hypothalamus is being understood in ever finer detail.

A kind of connection between the central nervous system and the immune system is made plausible by several unconnected observations, not the least of which is that some types of the lymphocytes involved in the body's immune response to, say, bacterial infections are found to carry receptors which recognize simple peptide hormones also found in the brain.

Some of the connections have been reviewed by David Maclean and Seymour Reichlin (Psychoneuroimmunology 12, $475 ; 1981$ ), and can plainly take several different forms. Maclean and Reichlin offer the interaction of the hypothalamus and the pituitary as the most interesting source of materials that may modify immune function. Some possible interactions are direct, as with the pituitary hormone that appears directly to stimulate the development of cells in the thymus, the organ in which $\mathrm{T}$-cells become recognizably different from cells that produce antibodies. But the best-known routes by which pituitary hormones may affect the immune system are indirect, involving the stimulation of the adrenal cortex by hormones such as adrenocorticotropic hormone.

This imbalance is unlikely to persist for long. As techniques improve for distinguishing between $T$-cells in different stages of their maturation and for sustaining them in culture, there has naturally been an upsurge of interest in the measurement of response by lymphocytes to hormones of various kinds. It seems to be established that the steroid hormones of the adrenal cortex more markedly stimulate lymphocytes at early rather than late stages in their differentiation, which may suggest how the composition of the circulating lymphocytes may be controlled by peptide hormones.

And then, it seems, some peptide hormones stimulate $\mathrm{T}$-cells to produce lymphokines (such as interleukin-2 but also interferon) and others have the opposite effect. The more radical psychoimmunologists talk as if there is no state of mind which is not faithfully reflected by a state of the immune system.

Others go further. J. Edwin Blalock of the University of Texas at Galveston, writing in the Journal of Immunology in March $(132,1067 ; 1984)$ under the title "The immune system as a sensory organ", argues that the interaction between the central nervous system and the immune system must be reciprocal, with peptide hormones of the pituitary and lymphokines secreted by lymphocytes having similar functions in the blood and with antigenic stimuli such as different kinds of bacterial infections producing physiological and even behavioural changes in the infected animal. He does not quite say that the emotional consequences of measles and tuberculosis infections should be distinguishable - but of course, they are.

The other line of inquiry that has helped put psychoimmunology on its feet are experiments with whole animals. In many ways, these are adjuncts of the classical investigations of the effects of stress on the system of adrenal hormones and thus on blood pressure, heart rate and so on.

In one typical investigation (Laudenslager, M.L. et al. Science 221, 568; 1983), groups of a dozen rats were given electric shocks of two kinds, and the sensitivity of their lymphocytes to artificially provoked cell division by the materials called mitogens assessed. The more seriously stressed rats were found to have the least easily stimulated lymphocytes at the end of the experiment.

Surprisingly, very similar investigations can be mounted with people. Thus S.J. Schleifer et al. have tackled directly the question of the immunological consequences of bereavement by means of a prospective study among men whose wives had been found to have breast cancer. Those who were eventually widowed have been reported (J. Am. med. Ass. 250, 374; 1984) to have had circulating lymphocytes less responsive to the effect of mitogens, just like the rats given electric shocks.

Investigations such as these, while timeconsuming and costly, at least have the merit of being practicable and, once mounted, easy to interpret. The snag is that statistically significant samples are accumulated only slowly, and at a high cost.

Why, in these circumstances, does there persist a stout band of near-sceptics convinced that too much is being made, at this stage, of the explanatory value of psychoimmunology? There are several reasons, not the least of which is that very similar lines of argument, more accurately, hypotheses, have been used within living memory speciously to suggest links between a person's chance of developing cancer and his or her state of mind.

Second, because knowledge of T-cells and their function is growing so quickly, it is necessarily difficult to design systems for assaying the effects of hormones, or of states of mind, on lymphocytes that are reproducible and significant.

Third, one rather crucial question seems to have been left for too long aside. If it should be that a person's state of mind, say grief, may affect the quality of his immune system, how does it then transpire that he or she will be more likely to die of heart attack or stroke or even in a road accident? In short, the explanation is likely to be part of a more complicated tale. John Maddox 